\title{
ПОНЯТИЕ ИДЕИ СВОБОДЫ В АНТИЧНОЙ И СРЕДНЕВЕКОВОЙ ФИЛОСОФИИ
}

\begin{abstract}
Аннотация. В статье прослеживается становление и развитие понятия идеи свободы в Античнойи Средневековой европейской философской традиции. На основе проведенного анализа становится ясно, что современное понимание идеи свободы, равно как и идей права, справедливости и гражданского общества берут свои истоки еще в философии Античности и Средневековъя. Последующее движение философской и политологической мысли лишь более детально разрабатывает как теоретические категории, так и «прикладные» аспекты данного понятия на основе которого строятся современные демократические государства.
\end{abstract}

Ключевъе слова: Философия, идея свободы, античность, средневековъе, свобода воли, человек, общество, благо, бог, выбор.

\section{1. Зарождение первъх представлений о свободе в древнегреческой философии}

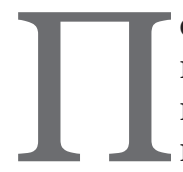
о мнению историков философии, изначально ни греческое слово $\varepsilon \lambda \varepsilon v v \rho \varepsilon l \alpha$, ни латинское «libertas» не имели специфически философского значения. В мышлении древних греков и римлян понятие идеи свободы не было выражено ни тематически, ни терминологически ${ }^{1}$. Основной интерес древнегреческих мыслителей в то время был направлен на осмысление таких понятий, как необходимость, судьба или случай. К примеру, в трудах Гесиода или Анаксимандра, мы можем найти фрагменты, где говорится о судьбе как господстве божественной силы в жизни человека. А это, в свою очередь, уже дает нам основания трактовать данные размышления как размышления о возможной свободе или несвободе человеческих действий и поступков.

Понятие «быть свободным» возникает намного раньше, чем собственно понятие свободы. Быть свободным, еще в понимании Гомера, означало жить на своей родной земле и не находиться ни под чьим либо господством - в противоположность к военнопленным, которые рассматривались тогда как рабы. После Гомера понятие «быть свободным» уже прочно укореняется в словоупо-

${ }^{1}$ Cp.: Warnach, W. Freiheit // Ritter, J. (Hg.) Historisches Wörterbuch der Philosophie. Bd. 2. Basel / Stuttgart, 1972. S. 1064. треблении греческого полиса. Это означает, что полис сам по себе олицетворяет свободную землю, а свободным человеком является тот, кто живет на земле полиса. В греческом полисе должен был господствовать разум, а насилие ограничиваться системой права.

Помимо этого, изменение акцентов в понимании свободы человека проявилось еще и в том, что противоположным понятием по отношению к понятию «свободный человек» стает не понятие «раба», а понятие «не-грека» или «варвара». При этом понятие свободы обосновывается в идее бога и означает не состояние анархии, где каждый волен поступать по собственному усмотрению, а равенство всех граждан полиса перед законом.

Наряду с этим понятием свободы, имеющим непосредственное отношение к полису как гаранту свободы человека, в древнегреческой философии можно найти и понятие свободной воли как обозначение индивидуальной свободы человека. У Гомера свободным является тот человек, который не испытывает никакого внешнего принуждения и действует, исходя из желаний собственной природы.

Употребление понятия «свобода» в собственно философском смысле впервые встречается у Софистов, когда закон (Nomos) радикально противопоставляется природе (Physis). Софисты как бы «отделяют» понятие свободы от полиса и полисной демократии и противопоставляют его полису. Таким образом, свобода начинает по- 


\section{Философия и культура 5(65) • 2013}

ниматься как «внутренняя свобода» отдельного индивидуума. Отныне состояние свободы может быть достигнуто даже независимо от права или политики. Таким образом, свобода начинает пониматься как достижение гармонии логоса с природой${ }^{2}$. Именно у стоиков в наибольшей степени проявиляется тенденция рассматривать понятие свободы как «внутреннее» понятие человека (в особенности у Эпиктета). Это была попытка вывести понятие свободы из сферы политического словоупотребления и рассмотреть его в качестве дихотомии «внутренняя-внешняя» свобода, что позднее нашло продолжение в европейской философской традиции. Эта дихотомия, но уже в более острой форме, была сформулирована позднее и в средневекой философии.

«Природа» в понимании софистов есть то, что само себя разворачивает без какого-либо внешнего принуждения. То, что природа в своей свободе создает, является необходимым, в отличие от законов, созданных человеком. И хотя человек стремится в своей жизни к достижению удовольствий, не ко всякому удовольствию нужно стремиться. Демокрит полагал, что оправданно стремление только к нравственно прекрасному. По свидетельству Ксенофона, сократическое понимание свободы является «деланием лучшего». Такое понимание свободы уже содержит в себе знание того, что является «лучшим» и того, как совершается нравственный выбор человеком. Именно здесь выбор впервые в философии понимается в смысле нравственного выбора. Для знания «лучшего» необходима особая способность - «искусство измерения души». Можно утверждать, что Сократ развивал, так сказать, «просветительскую» точку зрения - все одинаково ищут добра, но не все знают, в чем оно состоит. Разум должен освобождать человека от низших побуждений и желаний и, таким образом, привести его к добру.

Киники восприняли в учении Сократа исключительно момент автаркии и развили его в направлении радикального отказа от всех человеческих потребностей. Особенно выпукло это проявилось у Диогена Синопского, который говорил о развитии «внутренней свободы» нидивида путем увеличения радикальной независимости как от внешних (насилие), так и от внутренних (стремления, страсти) проявлений принуждений. В целом можно

\footnotetext{
${ }^{2}$ См. подробнее: Conze, W. Freiheit // Brunner, O., Conze, W., Koselleck, R. (Hgg.) Geschichtliche Grundbegriffe. Historisches Lexikon zur politisch-sozialen Sprache in Deutschland. Bd. 2. Stuttgart, 1998. S. 435 f.
}

сказать, что древнегреческие представления о свободе были тесно связаны с идеей рока, предназначения или судьбы.

У Платона понятие свободы определяется почти исключительно в рамках полисного понимания свободы как бытия блага. Благо является совершенным понятием и оно делает также совершенным и бытие. Понятие автаркии (независимости), использовавшееся в языке полиса, является и основным определением свободы: свободным является тот человек, чьи действия направлены на достижение блага, поскольку благо в своей автаркии и несет с собой свободу. Душа человека может быть упорядочена благодаря самоконтролю и размышлениям, также как и полис может быть упорядочен благодаря народному собранию и единству. Свобода, таким образом, не независимость отдельной личности от общества, а твердое владение собой и стремление к благу. В поздних диалогах Платона высшей формой свободы выступает свобода как дружба - и она реализуется в обществе, в «совершенном» обществе полиса. Как и любовь к самому себе, которую развивает каждый гражданин, дружба является совершенным отражением автаркии блага как волящего самого себя ${ }^{3}$.

Сократ и Платон сформировали новый подход по отношению к категориям свободы и ответственности: вменение у них более устойчиво «соотнесено» с произвольностью решения и действий индивида, моральность является главным нравственным достижением или благом, а свобода уже трактуется как способность к добру4. Ответственность у Платона еще не вполне моральная категория; тем не менее она уже не рассматривается в соотнесении человека лишь с природой и космосом.

Человек, в отличие от животных, способен к ответственности, поскольку у него есть знание морально и должного. Добродетельность действия отождествляется с разумностью индивида. Для того, чтобы оправдать божество, Платон развивает свою теодицею, согласно которой, каждая душа самостоятельно выбирает свой путь и судьбу, но одновременно и несет ответственность за свой собственный выбор («Это вина избирающего; бог

\footnotetext{
${ }^{3}$ Cм.: Warnach, W. Freiheit // Ritter, J. (Hg.) Historisches Wörterbuch der Philosophie. Bd. 2. Basel / Stuttgart, 1972. S. 1068.

${ }^{4}$ Ср.: Столяров, А.А. Свобода // Новая философская энциклопедия: в 4 т. / под ред. В. Степина, А. Гусейнова, Г. Семигина, А. Огурцова. М., 2010. С. 504
} 


\section{Философия свободы}

невиновен»). Следует однако отметить, что Платон был еще далек от того, чтобы приписать индивиду его автономию. По Платону, свобода человека раскрывается в его аскетическом состоянии, в стремлении человека к знанию и благу.

В исторической перспективе можно отметить, что влияние идей Платона было недостаточным, чтобы только с помощью использования понятия фатализма сделать более приемлимым восприятие такой «смелой» для того времени мысли как свобода человеческих действий или же свобода человеческой воли. Это и неудивительно, поскольку Платону не удается разрешить «парадокс ответственности» он не смог объяснить, как можно выбирать «собственный характер», без того, чтобы, с одной стороны, не быть детерминированным через некий «протохарактер» и, с другой стороны, в своем выборе не следовать случайности или же произволу5.

Аристотель выступает против Платоновской концепции свободы как автаркии блага. Аристотель говорит о человеке как о деятельном существе, которое отличается от всех других существ своей способностью к свободному выбору. Выбор является не только чистым знанием, но и также стремлением, волевым актом. В конце-концов, для Аристотеля также, как и для Платона, совершенное знание блага должно направлять наши действия и стремления к добродетелям, а свобода, в итоге, должна быть понята как совершенная автаркия. Автаркия проявляется в порядке полиса, основанном на принципах разума так, что самый свободный человек оказывается в наибольшей степени связан знанием порядка полиса. Однако нужно заметить, что Аристотелю все-же удалось выйти за рамки греческого полисного мышления. Для Аристотеля высшая автаркия мудрецов состояла в обладании счастьем, т.е. возможности жить в соответствии с желаниями собственной воли (а у мудрецов все созвучно Логосу).

Можно сказать, что Аристотель, как и стоики, определял свободу, имеющую своей предпосылкой ответственность, исключительно как свободу человеческих действий или свободу спонтанности. Человеческое действие является свободным в том смысле, что оно исходит из «собственного воздействия» или же является «sua sponte», как говорили схоласты ${ }^{6}$.

\footnotetext{
${ }^{5}$ Cp.: Steinvorth, U. Freiheitstheorien in der Philosophie der Neuzeit. Darmstadt, 1987. S. 15.

${ }^{6}$ Cp.: Steinvorth, U. Freiheitstheorien in der Philosophie der Neuzeit. Darmstadt, 1987. S. 16.
}

Аристотель говорит о свободе как о произвольности, а в «Никомаховой этике» он рассмаривает связь понятия свободы с понятием добродетели. Непроизвольными являются те наши действия, которые совершены подневольно - либо под влиянием природных сил, либо под воздействием чьей-то власти, а также по неведению (когда человек не имеет понятия о возможных последствиях своих действий). Однако даже действия, считающиеся произвольными, не всегда выполняются по собственной воле (осознанно). Аристотель классифицирует произвольные действия индивида следующим образом: это намеренные или преднамеренные поступки, совершающиеся человеком сознательно. Выбор при этом совершается самим человеком и зависит от средств достижения цели и способов претворения этих средств в действительность.

С философией Аристотеля также связан важный момент в осмыслении свободы воли человека. «Волевое» понимается у него как самоопределение разума, которое позволяет говорить о «спонтанности» произвола и выводить понятие о независимости решений разума из понятия о самом решении. «Добровольное» Аристотель трактует как то, что непосредственно зависит от воли индивида. Одна из важных идей Аристотеля состояла в том, что он говорит о разуме как источнике специфической причинности, отличной от природы или случая. Произвольное - это то, причина чего находится в совершающемся действии, а вменение относится только к разумно-произвольным действиям. Как отмечает Столяров, понятие «виновности» получает у Аристотеля субъективно-персональный смысл. Аристотель вводит и такие понятия как «воля», «выбор» (или "решение»), «произвольное», «цель» и т.д. Все эти категории были «воприняты Стоей, а через нее перешли к римским авторам и в патристику» 7 .

После распада греческого полиса понятие свободы начинает все чаще соотноситься с внутренней свободой индивида. Поэтому на первый план выдвигается вопрос о бытии и способе существования отдельного индивида. В этике стоицизма (Хрисипп) свобода индивида состоит в том, что он может своим разумом и волей противостоять судьбе как тому, что ему неподвластно. Стоики в определенном смысле развивали идеи Платона.

\footnotetext{
Столяров, А.А. Свобода // Новая философская энциклопедия: в 4 т. / под ред. В. Степина, А. Гусейнова, Г. Семигина, А. Огурцова. М., 2010. С. 504.
} 


\section{Философия и культура 5(65) • 2013}

Они полагали, что если зло на земле не может быть свойством космической причинности, то оно проистекает только от человека. Стоики считали, что решения разума являются источником спонтанной причинности и - в этом смысле - не могут быть свободными. Однако, решения разума должны быть свободными, чтобы его намерения стали реализуемыми.

Эпикур стремится вывести произвол из поля действия внешнего детерминизма и «привязать» его к произвольности действия. Но поставив на место детерминизма судьбы детерминизм случая, Эпикур уже не мог обосновать основы нравственного решения. По мнению Сенеки, свобода является «superiores esse» своебразным «противовесом» низшим побуждениям нашей души, различным аффектам и жизненным обстоятельствам. В своем высшем проявлении свобода проявляется в воле бога - свобода является нашей «царственной» привилегией - необходимо видеть себя свободным в повиновении богу.

В наивысшей степени стоическое понятие «внутренней» свободы получает свое развитие у Эпиктета. Свобода является «произведением» и высшим благом в человеке. Поскольку то, что мы знаем, находится внутри нас, то свобода (в негативном смысле этого слова) состоит в том, чтобы «отпустить» то, что находится «вне нас». Позивно Эпиктет понимал свободу как желание собственных стремлений («свободным является тот, у которого все происходит по собственным свободным решениям ${ }^{8}$ ). И тем не менее, нужно «следовать богу», а точнее - воле бога. Именно в этом и проявляется особенно остро диалектическое понимание свободы у стоиков: благодаря своему послушанию богу человек становится свободным по отношению к богу, то есть, можно сказать, человек сам становится подобным богу.

Представление о нравственной автономии и связи свободы и вменяемости действия особенно ярко было раскрыто у Плотина. Плотин ставит вопрос о таком бытии, чьим способом существования является свобода, бытии, которое само воздействует на свое существование. У человека сущность не совпадает с самообладанием, поэтому мы и не являемся «господами» своего бытия. Сам человек не может быть свободным, свободным может быть только вечное в человеке - его душа. Тело же связывают как законы природы, так и законы общества. При этом Плотин различает

\footnotetext{
${ }^{8}$ Epiktet, Diss. I, 12, 9.
}

между свободой полного господства над собой (собственно свободой) и более низкой ступенью свободы - свободы выбора. Человеческая свобода, как полагает Плотин, находит свой свовершенный вид в стремлении человека к Единому.

При этом размышления Плотина о свободе и внутренней ответственности человека имеют явный правовой оттенок. В Античности нравственность и право еще не различались друг от друга, так как это было сделано позднее в Средневековье и Новое время.

Онтологическое обоснование свободы в Неоплатонизме в наибольшей степени будет продолжено у Ямвлиха и будет перенесено при этом уже в плоскость теологии. У Ямвлиха речь идет не свободном действии или поступках, а о об освобождении в смысле спасения от мира необходимости (природы) и движении в сторону наимогущественнейшего бытия - к божественному. Человек в этом акте теургии играет роль «сопутствующей причины», решающим здесь является лишь передача себя под силы воздействия «божественной силы», когда душа индивида сможет раскрыться в высшей степени. Высшим актом человеческой свободы является познание бога - таким образом и абсолютная свобода божественного воздействия на дух человека приходит к своему совершенству.

У Прокла размышления о свободе приобретают следующий вид: по его мнению, свободна лишь «в себе и на себя саму опирающаяся духовная природа». Свобода направлена на саму себя как на свое «собственное благо» и не нуждается больше ни в чем. Свобода - это то, что является соразмерной поддержкой бытия духа, она является «свободной готовностью служить» богу в смысле Платона. Концепция Прокла о понятии свободы является последней в ряду античных философов, занимающихся апорией «свободы и необходимости» и позволяет перейти к рассотрению этого понятия в эпоху Средневековья.

\section{2. «Боэсественное откровение» как источник свободы в Средневековъе}

Эпоха Средневековья со стоящими в центре философских дискуссий Библией и божественным откровением, радикально изменила саму постановку вопроса о человеческой свободе. Как отмечает Плотников, христианство произвело два решаюших поворота в человеческом мышлении: 


\section{Философия свободы}

- оно радикально трансформировало моральный императив, поставив в центр рассмотрения благо ближнего - именно таким образом сфера этики была отделена от сферы права;

- христианство «видоизменило» теодицею, заменив имперсональный космический детерминизм уникальной божественной причинностью9.

Поэтому даже в тексте самой Библии можно проследить последовательное видоизмение значения понятия идеи свободы как философской категории. Так, в Ветхом Завете речь идет лишь о свободе Яхве как освободителя заключенных изпод стражи - это была «священная» служба Яхве. Из этого видно, что ветхозаветная интерпретация понятия свободы представляет собой понимание свободы не как атрибута божественного бытия, а лишь как соответствующую деятельность по освобождению конкретных людей. И хотя о свободе людей в ветхозаветных текстах речи напрямую и не ведется, можно увидеть, что сам характер божественных заповедей, где говорится о грехах и наказаниях за эти грехи, а также о раскаянии, содержит в себе в скрытом виде некие зачатки понятия свободы (и прежде всего, свободы решений).

В Новом Завете продолжены традиции Ветхого Завета: освободительное деяние бога достигает своей вершины в акте освобождения Иисуса Христа.

Собственно философские рефлексии о понятии свободы в Средневековье впервые можно найти у Филона Александрийского. Сначала он развивает стоические мотивы о понятии свободы в своих текстах; позднее Филон Александрийский использует уже идеи Платона. По мнению Филона, свободным является только бог, единый бог, «ни на что не опирающееся» и как «само себя наполняющее и самодостаточное» высшее бытие. Бог является настолько свободным даже и по отношению к самому себе, что он может быть творцом вселенной без привлечния какого-либо демиурга. Ведь бог соединяет в себе как благо, из которого все возникло, так и силу, благодаря которой он управляет всем миром. Свободным человеком является тот, кому бог дарует свободу. Бог может одарить человека свободой, поскольку он сотворил человека как неразрушимую духовную сущность.

\footnotetext{
9 Столяров, А.А. Свобода // Новая философская энциклопедия: в 4 т. / под ред. В. Степина, А. Гусейнова, Г. Семигина, А. Огурцова. М., 2010. С. 505.
}

Когда исследователи пытаются подробно анализировать средневековые философские тексты, им очень сложно отделить теологические понятия от собственно философских высказываний. Очень часто у средневековых философов традиционные философские понятия, имеющие древнегреческое происхождение, «наполняются» чуждым им религиозным содержанием ${ }^{10}$. К примеру, в изложении древнегреческой философии Апологетами часто происходит подмена исходных понятий богословскими понятиями.

Так, Юстинус [Justinus] в своей «Первой апологии» развивает перипатетическое учение о свободе и формулирует тезис о том, что «один человек, исходя из своей судьбы становится добрым, а другой - злым». Еще одно высказывание Юстинуса говорит о том, что человек, «исходя из своего свободного решения способен как творить справедливое, так и избегать его». Таким образом, у него четко просматривается постановка вопроса о свободе как о свободе выбора. Постепенно Юстинус отходит от античных представлений о свободе и начинает задаваться вопросом, который являлся центральным для всей средневековой философии: вопросом о совместимости божественного предопределения и человеческой свободы.

Антиномичный характер отношения между божественной милостью и человеческой свободой особенно ярко выражен в текстах Климента Александрийского. Климент различает природную склонность людей к добру от собственно «свободы» в смысле apatheia. И если в первом случае обосновывается смысл человеческих деяний, то во втором случае четко видно, что истинной свободой является только та свобода, к которой способен лишь бог. Божественная воля проявляется в том, что мы в своих желаниях выбираем благо и таким образом, освобождаем самих себя. Arete, таким образом, означает спасение, поскольку божественный порядок вещей является таковым, что человек как свободная сущность от природы т.е. естественным образом стремится к благу. «Свободное действие» состоит в отдаче себя божественной воле.

Ориген развивает учение Климента Александрийского и говорит о том, что обладание свободой и отличает людей от всех не-духовных сущностей. Наша способность быть хорошими или плохими людьми не в нашей природе или игре случая (фа-

${ }^{10}$ Cp.: Warnach, W. Freiheit // Ritter, J. (Hg.) Historisches Wörterbuch der Philosophie. Bd. 2. Basel / Stuttgart, 1972. S. 1076. 


\section{Философия и культура 5(65) • 2013}

тум). Эта способность является лишь результатом нашего свободного выбора. По мнению Оригена, люди обладают естественной способностью различать добро и зло, мы можем также и оперировать этими двумя понятиями. Однако, способность выбирать добро и отвергать зло является уже совершенно особенным актом. Подобный выбор не только свидетельствует о наших плохих и хороших деяниях, - он характеризует всю нашу сущность. Поскольку благо (или бог) является идентичным с самим бытием, а зло - с небытием, то тот человек, который избегает участия в делании блага (бытия), скатывается в небытие.

Позднее акценты несколько смещаются и уже у Грегора из Ниссы [Gregor von Nissa], равно как и у Псевдодионисия центральным становится вопрос о смысле человеческой жизни, заключающимся в познании бога, божественного знания и предначертания. По мнению Грегора, обладание свободой у людей является необходимой предпосылкой для достижения человеком всеобъемлющего познания божественного знания. Здесь можно увидеть один интересный ньюанс: если у монаха Грегора говорится о неограниченной свободе воли человека, то в спекулятивно-мистической теологии следующего столетия - у Псевдодионисия - речь идет о свободе как о повороте человека к сверхбожественному как единству всего сущего ${ }^{11}$.

Постепенно в средневековой философии начинает ставиться вопрос не только о божественной сущости, но и о природе человека. Так, Максимус [Maximos der Bekenner] различает в воле человека, созданного «по образу и подобию божьему» два следующих момента: «естественная воля» человека как свободное проявление его сущности и «сознательно направленная воля» личности на познание своей собственной сущности. Различение, проведенное в теологии по поводу двойной воли Христа - божественной и человеческой позволяет Максимусу сформулировать собственно человеческое «измерение» свободы: свобода, это божественная мудрость человеческого существования, существования как личности. Свобода, проистекающая из природы человека, означает осуществление божественной мудрости в деятельности отдельной личности.

Немезиос [Nemesios], опиравшийся на Аристотелевское учение о неотделимости способности принятия свободных решений от духовной

${ }^{11}$ Cp.: Warnach, W. Freiheit // Ritter, J. (Hg.) Historisches Wörterbuch der Philosophie. Bd. 2. Basel / Stuttgart, 1972. S. 1080. природы человека, ставит вопрос о теодицее и объяснении существования зла в мире. Немезиос полагает, что бог как творец человека лишь в последнюю очередь может быть ответственен за появление и существование зла в мире. Именно из способности человека принимать решения, иными словами, выбирать, из свободы человека и проистекает зло.

У Августина особенно четко можно проследить мысль о том, что соотношение божественной воли (милости) и человеческой воли (или, в терминологии Августина, свободы) и есть как исходная точка, так и цель всех размышлений о свободе. Августин различает voluntas как основную действующую способность духовной природы человека от libertum arbitrium (свобода выбора - лат.) как высшей степени проявления этой способности в акте принятия решения. Это выделяет человека как духовную сущность из мира природы.

В своем раннем трактате «О свободном решении» Августин рассматривает проблему теодицеи и опирается при этом на идею рационалистического упорядочения состояния мира. Августин следует полностью классической традиции средневековой теологии и религиозной философии, когда подчеркивает, что бог не является ответственным за зло в мире, поскольку единственным источником зла на земле является человеческая воля. Существование морали лишь тогда становится возможным, когда субъект становится свободным от условий внешней причинности; индивид должен также иметь возможность делать выбор между добром и злом. Моральность при этом состоит в следовании человеком нравственному долгу. По мнению Августина, идея нравственного закона может выступать как мотив человеческого поведения. Позднее эта схема у Августина сменяется концепцией предопределения, которая достигает завершения в антипелагианских трактатах ${ }^{12}$ и приводит его к «окончательному разрыву с этическим рационализмом» ${ }^{13}$.

По мнению Августина, человек свободен в выборе не грешить, не поддаваться искушениям и вожделениям. Человек может быть спасенным благодаря лишь благодати божьей. От собственного выбора человека зависит, принять грех или же воздержаться от греха.

\footnotetext{
12 Таких, как, к примеру, «О благодати и свободном решении» и «О предопределении святых».

13 Столяров А.А. Свобода // Новая философская энциклопедия: в 4 т. / под ред. В. Степина, А. Гусейнова, Г. Семигина, А. Огурцова. М., 2010. С. 505.
} 


\section{Философия свободы}

Августин полагает, что воля является «причиной самой себя» и может быть определена через эту самопричинность. Это означает, что безусловная свобода человека, свойственная человеку как духовному существу и возвышающая его над остальным природным миром, ведет индивида к становлению его как личности, личности, созданной творцом. При этом воля человека может направлена как на низменныепобуждения (cupiditas), так и на свое высшее проявление - любовь к богу (caritas $=$ motus ad fruendum Duo).

Средневековое понимание свободы во многом основывается на основных идеях Августина о «De libero arbitrio». При этом происходит модификация некоторых сторон августиновского учения. Так, Ансельм Кентерберийский трактует liberum arbitrium не как нейтральную способность человека к произволу, а как свободу человека, направленную на достижение им добра. У схоластов в центр рассмотрения ставятся идеи Аристотеля о самодвижности души и самоопределения разума - в это время размышления Августина оказываются невостребованными. Интересно, что у Ансельма Кентерберийского и у Фомы Аквинского понятие свободы достигает еще более высокой степени абстракции и свобода начинает рассматриваться как чисто интеллектуальная способность, близкая к способности суждения. Воля является свободной от любых проявлений внешней необходимости и ее решения являются необходимостью сами для себя.

Ансельм Кентерберийский определяет свободу как цель, которую нам показывает разум, а воля выбирает эту цель. Фома Аквинский, испытавший сильное влияние идей Аристотеля о психологии выбора, понимает свободу как способность воли находить средства для достижения выбранной цели, при этом сама цель не являлась liberum arbitrium. Но для Фомы понятие свободы не исчерпывалось, как может показаться, «ценностно-нейтральной» трактовкой свободы как свободы выбора. Он говорит о модальностях свободы выбора и о сущности свободы как самостоятельной сущности, напрямую связанной с богом в его сотворении блага. Такое понимание свободы перенесло все внимание схоластов на вопрос о метафизических корнях понятия свободы. Бонавентура, к примеру, трактует свободу как независимость сущности, наделенной разумом.

В целом можно констатировать, что на исходе эпохи Античности было две главных традиции рассмотрения понятия свободы ${ }^{14}$ : в мистической

\footnotetext{
${ }^{14}$ Cp.: Warnach, W. Freiheit // Ritter, J. (Hg.) Historisches Wörter-
} buch der Philosophie. Bd. 2. Basel / Stuttgart, 1972. S. 1082. теологии христианского Востока свобода трактовалась как условие и исполнение «Theosis» через возвышение к переживанию бога - это линия идет от Иоанна Скотта Эриугены вплоть до Николая Кузанского. Другая линия рассматривала свободу как еще невызревшее диалектическое понятие о соотношении природы и божесвенной милости этими вопросами занимался как Оккам, так и позднее Мартин Лютер.

Оккама не интересует вопрос о том, является ли человеческая воля в принципе свободной. Он рассматривает свободу уже, говоря в терминах сегодняшней философии, с «теоретико-познавательной» точки зрения. Оккам полагает, что свободу нельзя обосновать с помощью аргументов разума - свободу можно изучать лишь как феномен внутренних переживаний индивида. Вопрос о свободе бога трактуется не как вопрос философствующего разума, а как область религиозной веры. Новым аспектом у Оккама является вопрос о том, что человек сам в состоянии сделать - до вмешательства бога. Ответ на этот вопрос у всех последующих схоластов звучит вполне в духе средневековой религиозной философии - свобода может привести человека к акту совершенной любви к богу и достижению в итоге божественной милости.

Важно отметить, что именно эта идея средневековой схоластики и позволила сделать следующий шаг в развитии понятия идеи свободы в философии. Подобная теологическая оценка liberum arbitrium должна была быть дополнена психологическим представлением о свободе как абсолютно недетерминированной воле. Именно отсюда и возникает гуманистическое понимание свободы как свободы по отношению к богу. Схоласты, рассматривали соотношение «творец-сотворенное» и при этом не подвергали сомнению примат бога в самопричинности воли. В средневековье свобода понималась как сотворенная богом. Далее акценты существенно меняются и философия Ренессанса уже трактует свободу как самопричинность людей по отношению к богу.

На смену liberum arbitrium приходит servum arbitrium (Мартин Лютер). У Лютера проблема человеческой свободы рассматривается хотя и теологическом ключе, но уже в одном ряду с другими темами: закон, заслуги, искупление и т.П. При этом, как известно, Лютер не придерживался жестких рамок схоластики и не пытался непременно показать, что человек получает свою свободу как дар божий. В этом виден разрыв Лю- 


\section{Философия и культура 5(65) • 2013}

тера с догматической теологией. Поскольку Лютер пытается обосновать свободу человека чисто философскими методами, то можно утверждать, что здесь речь идет уже о гуманистическом понимании категории свободы ${ }^{15}$. Лютер в своих работах рассматривает божественные деяния на одном метафизическом уровне с действиями и со свободой человека. Поэтому можно сказать, что он является прямым предшественником идей эпохи Возрождения.
Таким образом, можно заметить, что современное понимание идеи свободы, равно как и идей права, справедливости и гражданского общества берут свои истоки еще в философии Античности и Средневековья. Последующее развитие философской и политологической мысли лишь разрабатывает более детально категории идеи свободы, а также «прикладные» аспекты данного понятия на основе которого построены современные демократические государства.

\section{Список литературъ:}

1. Новая философская энциклопедия в 4 т. / под ред. В. Степина, А. Гусейнова, Г. Семигина, А. Огурцова. М., 2010.

2. Столяров, А.А. Свобода воли как проблема европейского морального сознания. Очерки истории: от Гомера до Лютера. М.: Греко-латинский кабинет Ю.А. Шичалина, 1999. 206 с.

3. Conze, W. Freiheit // Brunner, O., Conze, W., Koselleck, R. (Hgg.) Geschichtliche Grundbegriffe. Historisches Lexikon zur politisch-sozialen Sprache in Deutschland. Bd. 2. Stuttgart, 1998. S. 435 f.

4. Pesch, O. Freiheit // Ritter, J. (Hg.) Historisches Wörterbuch der Philosophie. Bd. 2. Basel / Stuttgart, 1972. S. 1087.

5. Steinvorth, U. Freiheitstheorien in der Philosophie der Neuzeit. Darmstadt, 1987.

6. Warnach, W. Freiheit // Ritter, J. (Hg.) Historisches Wörterbuch der Philosophie. Bd. 2. Basel / Stuttgart, 1972.

\section{References (transliteration):}

1. Novaya filosofskaya entsiklopediya v 4-kh tomakh / Pod red. V. Stepina, A. Guseynova, G. Semigina, A. Ogurtsova. M., 2010.

2. Stolyarov, A.A. Svoboda voli kak problema evropeyskogo moral'nogo soznaniya. Ocherki istorii: ot Gomera do Lyutera. M.: Greko-latinskiy kabinet Yu.A. Shichalina, 1999. $206 \mathrm{s.}$

3. Conze, W. Freiheit // Brunner, O., Conze, W., Koselleck, R. (Hgg.) Geschichtliche Grundbegriffe. Historisches Lexikon zur politisch-sozialen Sprache in Deutschland. Bd. 2. Stuttgart, 1998. S. 435 f.

4. Pesch, O. Freiheit // Ritter, J. (Hg.) Historisches Wörterbuch der Philosophie. Bd. 2. Basel / Stuttgart, 1972. S. 1087.

5. Steinvorth, U. Freiheitstheorien in der Philosophie der Neuzeit. Darmstadt, 1987.

6. Warnach, W. Freiheit // Ritter, J. (Hg.) Historisches Wörterbuch der Philosophie. Bd. 2. Basel / Stuttgart, 1972.

${ }^{15}$ Cp.: Pesch, O. Freiheit // Ritter, J. (Hg.) Historisches Wörterbuch der Philosophie. Bd. 2. Basel / Stuttgart, 1972. S. 1087. 